\title{
Defender la vida desde las trincheras:
}

\section{ejercicio del derecho a la asistencia y organización para la sobrevivencia en barrios populares de Salta durante la pandemia}

Defending life from the trenches: exercise of the right to assistance and organization for survival in popular neighborhoods of Salta during the pandemic

Gonzalo Juan José Fernández

Licenciado en Trabajo Social

(Universidad Nacional de Jujuy)

Docente e Investigador

(Universidad Nacional de Salta)

Becario doctoral (CONICET)

(Instituto de Investigaciones en Ciencias Sociales y

Humanidades)

Correo: gonzaloferna8@gmail.com 


\section{Resumen}

En el presente texto se tematiza sobre los modos de organización comunitaria llevados adelante desde Villa Floresta, un Barrio Popular de Salta capital. Se tratará de describir y analizar los singulares modos que tienen las comunidades más pobres de hacer trinchera, en post de la subsistencia, como potencia para la defensa de la vida. Teniendo como trasfondo la ineluctable crisis por pandemia de COVID-19 y luego de haber transitado un tiempo de resistencias condicionadas por la depresión económica global que esta provocó, queremos "tomar el pulso": la palabra y la acción de quienes habitan los barrios, para aproximar desde esos suelos, al horizonte de las luchas cotidianas que desarrollan las comunidades populares del norte de nuestro país. Nos interesa pensar las prácticas llevadas adelante en los barrios desde una analítica que se liga con el actual debate por desandar complejas tramas en torno a la asistencia como derecho. El tratamiento de este trabajo se desarrolla codificando prácticas discursivas y extra-discursivas: tanto de las personas que habitan los barrios, como de referentes de la administración del gobierno provincial; plasmadas en documentos periodísticos, consultando páginas del gobierno, programas y planes focalizados dirigidos a las poblaciones pobres.

\section{Palabras clave}

Derecho a la asistencia, Pobreza persistente, Gobierno de la pobreza, Trincheras populares.

\section{Abstract}

This text discusses the modes of community organization carried out from Villa Floresta, a popular neighborhood in Salta capital. It will try to describe and analyze the unique ways that the poorest communities have to make a "trench", in pursuit of subsistence, as a power for the defense of life. Against the background of the ineluctable crisis due to the COVID-19 pandemic and after having gone through a time of resistance conditioned by the global economic depression that it caused, we want to "take the pulse": the word and action of those who inhabit the neighborhoods, to from those soils to approach the horizon of the daily struggles that the popular communities of the north of our country develop. We are interested in thinking about the practices carried out in the neighborhoods, from an analytic that is linked to the current debate to retrace complex plots around care as a right. The treatment of this work is developed by codifying discursive and extra-discursive practices: both of the people who inhabit the neighborhoods; as referents of the provincial government administration, reflected in journalistic documents, consulting government pages, programs and focused plans aimed at poor populations.

\section{Keywords}

Right to assistance, Persistent poverty, Government of poverty, Popular trenches. 


\section{Introducción}

Ha pasado ya casi más de un año desde las primeras disposiciones preventivas de seguridad dictaminadas por la presidencia de la Nación Argentina en torno a la crisis socio-sanitaria por COVID-19 que golpeó a todo el mundo. La discrecionalidad de gobierno con la que cada jurisdicción provincial sobrellevó la pandemia, tuvo profundos efectos diferenciales sobre la población en general, lacerando gravemente la reproducción de las vidas de los sectores poblacionales pobres en particular.

El saldo de muertes que arrojó la pandemia en nuestro país, corresponde ya, al orden de los datos estadísticos que se guardará en la memoria de nuestro pueblo. Se verá en el tránsito de este tiempo turbulento, a mediano plazo, cuál es el impacto de las medidas tomadas por la salud pública estatal, en torno a una pandemia que aún continúa su decurso.

En la procura de la urgencia, de la atención y de la asistencia de los sectores populares de nuestro país se implementaron una serie de "políticas de salvataje"1, destinadas a sopesar la tensión del demoledor desfasaje económico que provocaron las medidas de Aislamiento Social y Preventivo (en adelante, ASPO) y las limitaciones a nivel general por el COVID-19. Estos recursos destinados a cubrir la acuciante crisis que ya vivían los sectores populares, aun antes de la pandemia, actuaron de manera tonificante sobre el magro cuerpo social y estrangulado de los barrios populares en toda la Argentina. Así también hay que decir que, los circuitos y mecanismos estatales de asistencia tomaron derivas restrictivas en algunos casos en la capital salteña, ocluyendo el acceso de recursos de primera necesidad en comedores y merenderos como los de Villa Floresta.

El recurso de la asistencia material como gestión gubernamental Estatal se torna, en tiempos de pandemia, crucial sobremanera; ya que en primera y en última instancia lo que se conjura de nuevo es el principio biopolítico y racista que pone en entredicho: vida y muerte. 
Lo que está en juego es la vida, el trasfondo de la lucha por el acceso al derecho y la astucia táctica que se pergeña desde las comunidades y grupos en los barrios populares en pos de "hacer trinchera" (Gramsci, 2014,), de acopiar recursos, siempre al límite del mínimo biológico y de la escasez material (Álvarez Leguizamón, 2015). En tanto desde dichas territorialidades, les vecines ${ }^{2}$ mancomunadamente se organizan en grupos en sus comunidades de vida para volver al munus ${ }^{3}$ colectivo en procura de la subsistencia, de la negociación y la presión activa a circuitos de gobierno estatal para asegurar derechos.

En un escenario donde domina un discurso bélico: el de "guerra global epidemiológica", las comunidades en las villas y asentamientos de Salta capital hacen base y se posicionan desde múltiples dispositivos territoriales: comedores, merenderos, centros vecinales y mesa de barrios populares. Son esas algunas de las trincheras locales desde donde se resiste a la precariedad global en la actualidad de Salta.

Este artículo viene a acoplarse al debate profundamente actualizado y complejo sobre el derecho a la asistencia pública-estatal en nuestro país y región (Campana Alabarce et al., 2020). Punto de paralaje político y aporético que, desde el Trabajo Social, adquirió un lugar y uso peyorativo-residual en la genealogía de su historia y que hasta ahora no se había vuelto a poner en discusión seriamente, pero que en la actualidad redunda en análisis y diagnósticos que giran en torno a las crisis y la cuestión social contemporánea.

Son vastos los estudios y enfoques en torno a pobreza en nuestro país y América Latina. Con todo, nuestra perspectiva analítica toma recursos de los estudios de gubernamentalidad (Foucault, 2011; Rose, 1996; Castro Gómez, 2010; Giavedoni, 2012; Campana Alabarce, 2018; Paulizzi, 2020), ponderando el gobierno de la pobreza como grilla analítica global.

2 Adherimos al lenguaje inclusivo y al modo nominal propuesto por Cátedra Paralela. Sin embargo, aclaramos que en ciertos casos usaremos el binarismo propuesto también como fuente por la revista. Cabe aclarar que no se intervendrán las expresiones explícitas y textuales codificadas en las entrevistas realizadas, aclarando que las personas que se entrevistaron no usaron el lenguaje inclusivo.

3 Nos recuerda Preciado que en latín el munus hace referencia al tributo que alguien debe pagar por vivir o formar parte de la comunidad. La comunidad se traduce como cum (con) munus (deber, ley, obligación, pero también ofrenda). (Preciado, 2020 citado en Amadeo, 2020). 
Asimismo, instrumentamos aportes de las Ciencias Sociales y la Filosofía Política, buscando enriquecer nuestros análisis. Mediados por una perspectiva metodológica que articula la investigación-acción-participativa (Holliday, 2013), desarrollamos un registro localizado y comprometido en nuestra indagación. Articulamos transgresivamente modos discontinuos de escritura, estos se expresan en desvíos y lateralidades ${ }^{4}$ alegóricas, buscando con ello plasmar en imágenes (Rivera Cusicanqui, 2015) las experiencias vividas en terreno.

\section{Los monstruos reaparecen en tiempos de crisis}

Decía Gramsci (1981) que en tiempos oscuros, plagados de crisis, lo morboso se revela: ahí donde las fuerzas sociales socavan y agrietan las lógicas de su devenir y cuando la transición de una temporalidad no termina de cuajar, por estar sumida en fugaces contingencias y aporías, se revela lo monstruoso y gris del momento histórico que vive la humanidad. Un período que no termina de saldar su deuda masiva de muerte, que deprime las economías de las personas trabajadoras en agobiante crisis, alineada a las lógicas apremiantes de la razón neoliberal y que hace transcurrir en lo agonístico a la humanidad toda, es el tiempo de monstruos de hoy. La nueva normalidad se resguarda inmadura aún: disoluta, inasible, ininteligible y silenciosa, espera.

Este tiempo de monstruos que engendró el COVID-19 hace mella profundamente en las territorialidades a nivel global: la masividad de la muerte humana y la subordinación de las vidas a la producción económica es el ataque más ostensible a la humanidad en "tiempos de guerra". Pero el resquebrajamiento de las lógicas económicas y relacionales de subsistencia del tejido societal, el debilitamiento disruptivo de los modos comunitarios de solidaridad social acrecentaron la incertidumbre, el individualismo a ultranza; promoviendo modos de Racismo de Estado (Foucault, 2014) y reconfigurados fascismos societarios (Boaventura, 2009).

4 Mediante ello se busca traslapar un modo discontinuo de escritura, apelando a la descripción minuciosa para desagregar aspectos codificados de las experiencias vividas y significadas, apelando a la metáfora y a la alegoría como recursos de utilidad simbólica (Rivera Cusicanqui, 2015). 
La discusión en el siglo pasado rondaba (y ronda aún) sobre la fractura de lo social ${ }^{5}$ como ataque directo de la racionalidad liberal y neoliberal a los llamados Estados protectores de Bienestar. Hoy por hoy, la apuesta se redobla: la fractura hace blanco en la dilución de lo social (la sociedad como tal), subordinando el sistema de derechos sociales y la justicia social como ámbitos contensivos, destinados a contrarrestar los modos violentos del repliegue de una economía salvaje, de la desigualdad social y en última instancia, sobre el resguardo de la vida: el ataque contemporáneo, nos menciona Brown “(...) se materializa sobre la sociedad y la justicia social en nombre de la libertad del mercado y del tradicionalismo moral es entonces una emanación directa de la racionalidad neoliberal” (2020:30).

Esta última es una de las tesis que Brown (2020) detalla en su última obra. A la botarga crítica del discurso neoliberal decimonónico que socava las garantías sociales en términos institucionales-estatales, el contraataque de la racionalidad neoliberal (Foucault, 2011) es sobre la carnadura relacional y contra el amplio espectro que implica la democracia, sus modos de ejercicio y sus diversas prácticas sociales en la actualidad.

Eso abstracto que llamamos “democracia” puede traducirse en una multiplicidad de ámbitos constitutivos que conducen a materializar el ejercicio de derechos, habilitando la condición de posibilidad de suturación del tejido social maltrecho por las lógicas neoliberales en la actualidad. Se configura también como el ámbito al que se apuesta reconfigurar y resignificar, desde diversas vertientes de la teoría política y social ${ }^{6}$. La democracia, tan vapuleada a lo largo de la historia, es

5 Nos recuerda Campana Alabarce: "Lo social, funciona como tejido contenedor y reparador que emerge como respuesta a la cuestión social, síntoma social de las desigualdades que sostiene la forma social capitalista y que implican un riesgo de integración social” (Castel, 1997; Murillo, 2008 en Campana Alabarce, 2014:83). Lo social es lo que el neoliberalismo se propone destruir. Friedrich Hayek la descalificó como una palabra sin sentido, Margaret Thatcher mencionó que se trataba de algo inexistente. Lo social y la propia sociedad es lo que debe excluirse de la agenda: un peyorativo para la derecha hoy en día (Brown, 2020).

6 Al respecto menciona Campana Alabarce (2020) que en el campo del Trabajo Social en Argentina, se han renovado los debates en torno a las dimensiones de lo asistencial de la intervención: "la necesidad de problematizar la asistencia como práctica válida y como campo privilegiado de intervención, de cara a situar su discusión en el terreno de los derechos sociales” (2020:51). 
demandada en clave del acceso de derechos humanos fundamentales en tiempos de pandemia por los sectores populares que sobreviven cruentamente la crisis sanitaria: el derecho a la asistencia está en el tapete de las disputas que aquí se suscitan.

Aproximaciones a la discusión sobre el derecho a la asistencia y el gobierno de la pobreza

El derecho a la asistencia ${ }^{7}$ está amalgamado con una demanda fundante en la actualidad: resignificar e identificar en profundidad el principio del ejercicio democrático (a nivel epistémico y político), no como discusión abstracta y vaciada de contenido, sino como locación en la que se disputan social e institucionalmente las lógicas y los circuitos para el acceso social efectivo a dicho derecho.

Por otra parte, las diatribas se abren ante las preguntas que discurren críticamente en nuestro tiempo, en Salta y en nuestro país. Se anticipa, a partir de su formulación, el diagnóstico de los modos de gobiernos locales y la caracterización de las políticas sociales y públicas que actúan en la mediación de la asistencia social:

¿Se trata de atender a la mayor parte de las necesidades de los sectores pobres o de menores ingresos, o se trata de atender a una parte de las necesidades de toda la población? (...) ¿la asistencia social atiende a los sectores identificados como pobres o brinda un conjunto de prestaciones sociales a toda la población en función de problemas sociales construidos y reconocidos como tales, independientemente de la posición en la estructura social? (Campana Alabarce, 2020:51).

El derrotero que desanda la asistencia social se enmarca en el sistema público Estatal de acción y protección social. Le competerá a la asistencia social actuar sobre las necesidades sociales de la población toda. El punto de partida y de ataque de la discusión que gira en torno

7 Desde el campo del Trabajo Social se ha vuelto a poner en el tapete en los últimos años la discusión que gira alrededor de las discusiones referentes a la dimensión asistencial de la intervención social, surgiendo la necesidad de problematizar la asistencia como práctica legítima y como campo privilegiado de intervención, con prospectiva a resituar los debates en el horizonte contensivo de los derechos sociales (Campana Alabarce, 2020). 
al lugar común de la concepción de la asistencia social, deriva en que aunque las necesidades más acuciantes se presenten con mayor incidencia en los sectores populares de menores ingresos, ello no implica que se trate de una política sectorizada para las necesidades del pobre (Campana Alabarce, 2020, 2018).

Lo cierto es que en tiempos de pandemia se han acrecentado las políticas asistenciales- "residuales" de individualización (Merklen, 2010) y focalización ${ }^{8}$ :

(...) una serie de prácticas que no se traducen en mejorar el bienestar, como quería la biopolítica, sino en mantener el límite de lo básico, cercano a la muerte por medio de la autoexploración de sus capacidades personales y comunitarias ya desgastadas (Álvarez Leguizamón, 2015:86).

A las bio-focopolitica ${ }^{9}$ de largo plazo, reconfiguradas en la actualidad y plasmadas en planes y programas "comunitaristas" de corte "familiaristas" (Clemente, 2014) con base en el discurso de Capital y Desarrollo Humano ${ }^{10}$ (Paulizzi, 2020; Campana Alabarce, 2014), se sumaron una serie de "políticas de salvataje” (Fernández, 2021) destinadas a cubrir la precarización producida por la crisis sanitaria en las poblaciones más pobres de Salta y el país: entre ellas podemos mencionar una de las más emblemáticas el $\mathrm{IFE}^{11}$, como la batería de

8 Se hace referencia a la orientación de las políticas sociales dirigida a los distintos grupos que deben asistirse y sobre los diversos problemas sociales asociados a la pobreza. Se asiste a una multiplicidad de programas que toman como población-blanco a los pobres (urbanos- rurales): juventud, mujeres, infancia, tercera edad, comunidades indígenas o minusválidos (Merklen, 2010).

9 Álvarez Leguizamón (2015) llamará de este modo a las políticas focales articulando la noción de biopolítica planteada por Foucault.

10 Aquí podemos destacar dos grandes "tecnologías de gobierno" (Foucault, 2011) destinadas a la intervención de poblaciones pobres e incardinadas en las lógicas del "gobierno de la pobreza" (Giavedoni, 2012) que gestionaron intervención en algunos sectores pobres de Salta capital, hoy urbanizados con servicios públicos básicos: el Programa de Mejoramiento Barrial (PROMEBA) y el Plan Nacional de Hábitat.

11 Ingreso Familiar de Emergencia (ANSES, 2021): seguro social dinerario que se ejecutó tres ocasiones en 2020, y estuvo destinado a trabajadores informales y monotributistas de las primeras categorías. Entre otras medidas ejecutadas por el gobierno Nacional, destinadas a paliar la precarización se destacan: el Programa de Recuperación Productiva 2 (REPRO 2): una herramienta para sostener el empleo de sectores con dificultades económicas (Argentina. gob. ar, 2020). 
políticas que lanzó desde 2020 el Consejo Nacional de Argentina contra el hambre ${ }^{12}$ se inscriben dentro de la grilla discursiva de acciones Estatales propendentes restitución de derechos fundamentales y que buscan palear el flagelo de la crisis.

Más allá de rejillas contensivas pero paliativas plasmadas en las llamadas políticas de salvataje, de los cambios de signo político y de los modelos de gobiernos en las últimas décadas en Argentina, los índices de pobreza, en su amplio espectro, oscilaron de manera parcial: $31,6 \%$ de hogares y, 42, $0 \%$, de población bajo la línea de la pobreza en el país en el segundo semestre de 2020 (INDEC, 2021). En tanto que en la provincia de Salta el índice de pobreza bajó en el segundo semestre de 2020: pasó de un 45, 5\% del primer semestre a un 41, $7 \%{ }^{13}$. Con todo, a comienzo de año 2021 se replicaban en uno de los diarios de tirada nacional alarmantes cifras publicadas por el organismo oficial de estadísticas (INDEC): "más de la mitad (57,7\%) de las personas de 0 a 14 años (en Argentina) son pobres" (Página 12, 2021: párr: 12).

Para dar cuenta de una profunda y crónica erosión "cuesta abajo", que hizo mella en la calidad de vida de varias generaciones de familias que proceden de sectores populares en el país y en Salta desde décadas atrás, hablaremos de la pobreza persistente. Comprendemos a ésta como una condición de privación generalizada, en la que a partir de una privación económica, se amalgaman de manera crítica, una serie de dimensiones referidas al hogar y su entorno cuyos indicadores manifiestan un déficit tan profundo que compromete la reproducción del grupo familiar y conviviente. Dicha categoría, se determina según los estándares que la sociedad establece como umbral para la asistencia de las necesidades más urgentes (Clemente, 2014).

Uno de los indicadores más ostensibles de la precariedad y de la pobreza que persiste en el tiempo en la vida comunitaria de los ba-

12 Entre dichas políticas sociales se pueden identificar: el programa Potenciar Trabajo, el Prohuerta, la Tarjeta Alimentar, Educación Alimentaria; dispositivos como el Registro Nacional de Comedores y Merenderos, Sembrar Soberanía Alimentaria, entre otros (Argentina contra el hambre, 2021)

13 La indigencia también se redujo un $11,4 \%$ a $10,3 \%$; un total de 265.982 pobres y 66.012 indigentes (INDEC, 2021) 
rrios populares se grafica en las secuencias iteradas de filas humanas abarrotadas en busca de alimentos en espacios socio-comunitarios. En lo que va del año 2021 crecieron en número los comedores y merenderos en Salta y el país. Según el Registro Nacional de Comedores y Merenderos, hasta diciembre de 2020 se registraban 600 comedores y merenderos en la provincia; sin embargo, hasta la fecha se cuadruplicó la presencia de dichos dispositivos comunitarios (Noviasky, 2021). Sumado a ello, se produjeron disruptivamente movilizaciones y cortes de calles en la capital salteña en los primeros meses de 2021. Las demandas sociales se fundamentan en el pedido de aumento de las partidas mensuales para la compra y provisión de alimentos destinados a comedores y merenderos donde se brinda asistencia vital a las comunidades pobres de los barrios populares de Salta capital.

Las protestas públicas se amplificaron también por el cierre indefectible de dichos dispositivos, producto de la falta de aprovisionamiento de los mencionados recursos. Las personas que concurren a merenderos y comedores, que forman parte de organizaciones de base y movimientos sociales levantan sus voces como gritos de demandas, en pos de ejercer el derecho a la asistencia estatal, frente a las restricciones económicas de la pandemia.

Consecuentemente analizamos a "la pobreza" como dispositivo interlapado a la racionalidad de la gubernamentalidad neoliberal (Foucault, 2011), destacando un singular modo de gobierno que hace base en las poblaciones pobres, actualizando la gestión paliativa de necesidades urgentes: la gestión de la pobreza. A este tipo de prácticas las comprendemos encabalgadas en las lógicas del "gobierno de la pobreza": modo de acción que modula la conducta de las poblaciones, no determinando un comportamiento específico, sino ofreciendo e instituyendo un campo más o menos amplio de alternativas y posibilidades, márgenes más o menos calculados sobre los que se intervendrá (Giavedoni, 2012).

Asimismo, Giavedoni (2012) da cuenta de algunas características del gobierno de la pobreza, refiriendo a aspectos que conforman un modo específico del ejercicio de poder sobre un sector particular de la población desde el que se destacan prácticas singulares y que se nominan como pobres: 
1) multidimensionalidad del gobierno (hay una pluralidad de instancias públicas y privadas involucradas en el gobierno de un problema); 2) hiperestatalización asistencial (hay una fuerte presencia del Estado en el mundo popular, en su dimensión asistencial); 3) gestión diferencial (que consolida las desigualdades o la inclusión en tanto excluidos) (Giavedoni, 2012, en Campana Alabarce, 2014:86).

Desde esta perspectiva, la pobreza se conforma en un blanco que ameritará ser intervenido como problema a gobernar ${ }^{14}$ (conformando a su vez un campo problemático) en el que intervendrán una diversidad de actores sociales e institucionales (del orden de lo público y lo privado).

\section{Entre ollas, maderas y cartón se levantan las trincheras populares}

La democracia está en otra parte distinta del Estado, incluso en las democracias, conjura Brown (2020), citando a Wolin. Es que al momento de pensar descentralizadamente los circuitos transitados clásicamente en torno a la asistencia social estatal, nos surgen cuestiones que, estimamos, se acoplan a un debate mucho más profundo y complejo; condicionado por una multiplicidad de variables ligadas a los modos de gobiernos en nuestro país y continente. Brechas genealógicas insondables y dispersas que se abren paso desde el siglo pasado hasta nuestro presente.

Yendo más lejos incluso, intuimos que el proyecto desandado por les colegas en la actualidad en torno al derecho a la asistencia (Campana Alabarce et al., 2020), permitirá al colectivo de Trabajo Social, la apertura a trastocar y revisar críticamente los modos esclerosados de practicar la asistencia social y el ejercicio político en su amplio espec-

14 Nos recuerda Giavedoni (2012) que "el gobierno de la seguridad", "el gobierno de la salud", "el gobierno de los niños", "el gobierno de las familias", "el gobierno de la actividad económica" abordan problemas que son intervenidos de manera específica, en las que se ven involucradas múltiples instancias que no son siempre estatales. Entre otros actores se pueden mencionar: autoridades religiosas, familiares, medios de comunicación, instituciones de justicia, la escuela, pedagogos, médicos, obras sociales, etc., un circuito de "autoridades" que ejercen modos específicos de poder tendientes a gestionar un problema. 
tro, en torno por ejemplo a la administración y gestión de recursos de los Estados en nuestra región sur, y/o a las burocracias Estatales, entre otros aspectos.

Dicha iniciativa de indagación crítica nos posibilitará quizás desplazamientos epistémicos, en relación a la posibilidad de reposicionar propuestas reales para pensar concienzudamente la tan evocada "democracia" y, partiendo de allí, se pueda ir más allá del sentido común-abstracto, mediante la propuesta de nuevos contenidos prácticos y nominales a partir de diagnósticos locales, en torno a la cuestión social contemporánea.

Como preguntas que se incardinan en la escritura de este artículo, amalgamadas al proyecto general de revisión crítica en torno al derecho a la asistencia nos surge: ¿es posible desarrollar modos alternativos, más allá de aquellos hasta ahora transitados, en torno a la asistencia a las poblaciones pobres? ¿Cómo devolver el estatus de la asistencia como derecho ciudadano más allá de la implementación de políticas focales destinadas a las poblaciones pobres, teniendo en cuenta las brechas de profunda desigualdad en nuestra región? ¿De qué manera contribuir a trastocar los roles en el ejercicio de poder-saber que los representantes estatales/ sujetos del saber-poder (trabajadores sociales, entre otres) ejercieron tradicionalmente? ¿Cómo recepcionar la organización activa, la torsión y la reconfiguración de sentidos que se practican en las comunidades de los barrios populares más allá de las lógicas de las políticas públicas sociales empaquetadas?

En lo mediato y desde nuestro punto de paralaje o lugar de enunciación crítico podemos dar cuenta del transcurso de singulares prácticas que desandan los colectivos sociales en los barrios populares de Salta Capital, en pos del ejercicio del derecho a la asistencia y por la sobrevivencia en el marco de la crisis socio-sanitaria. Apelamos a rememorar nuestro trabajo de acompañamiento e investigación participativa en Villa Floresta (Holliday, 2013), destacando las experiencias y la palabra de quienes habitan el lugar. 


\section{Arrancar el derecho a la asistencia}

Carlos ${ }^{15}$ era colaborador activo del comedor Bella Vista ubicado en la zona norte alta de Villa Floresta, sector que se constituye en la periferia de la periferia, en referencia al casco céntrico de la capital de Salta. Desde allí, trabajaba hace 5 años activamente en la colecta de alimentos provenientes de donaciones (empresas y comercios), realizando sorteos y comunicando desde el programa de radio que conduce, con el fin de abastecer al comedor Bella Vista (luego devenido merendero). Junto a Guadalupe Villanueva y otras vecinas iniciaron una labor social de asistencia sumamente necesaria, en el barrio popular Villa Floresta.

El comedor que en principio abastecía a 65 familias de la parte más alta de Floresta, tuvo que dejar de funcionar en varias ocasiones por la falta de provisión de recursos, ya que los alimentos se preparaban con la "ayuda" y colaboración de particulares. Aunque desde fines del año pasado el Ministerio de Desarrollo Social de la Provincia, inició asistencia material de alimentos. Provisión intermitente y limitada que justificó el cierre definitivo del dispositivo de contención Bella Vista:

Para nosotros el comedor cumplía una función social muy importante en el barrio, de asistencia de alimentos, de contención de situaciones de violencia en las familias y mediación ante otras instituciones como la policía. Surgieron muchos merenderos y comedores en este tiempo de pandemia, la mayoría con bandera política y no está mal que así sea, la gente busca refugio y contención en estos lugares. A nosotros nos dejaron de ayudar por no levantar banderas políticas (...) a la ayuda Estatal se la arrancamos a Desarrollo Social, no es que nos las dieron porque hicimos los trámites (...) no, nosotros no les correspondíamos políticamente (...) los políticos son políticos, se pelean arriba y tranzan bajo la mesa (Carlos, vecino de Villa Floresta, 30 de julio de 2021). 
En la palabra encrispada de Carlos se trasluce una "impotencia benigna” pero sin asidero que la contenga. Nos comentó de los circuitos transitados para conseguir las donaciones destinadas al comedor; nos mencionó de la solidaridad y entrega de les artistas y comerciantes; nos habló de la denuncia al Ministerio de Desarrollo Social que gestionaron mediante un funcionario en Cámara de Diputados por que la partida de alimentos y limpieza llegaba al cabo de dos meses una vez iniciada la cuarentena, y la gente en el barrio ya no podía esperar.

Guadalupe Villanueva, otra de las integrantes fundadoras del comedor llevó adelante gestiones para "arrancar los recursos" a la administración provincial, porque entiende a estos como "el derecho de la gente" y, que hasta hace algunos años atrás, el comedor jamás había recibido. El entredicho convulsionó cuando el funcionario del Ministerio de Desarrollo Social Ignacio González, admitió que el comedor Bella Vista recibía mercadería de la provincia. En una nota periodística, Villanueva mencionó:

Nunca habíamos recibido nada e hicimos la denuncia pública", dijo Guadalupe Villanueva, a cargo del comedor, al hablar con Salta/12. Afirmó que tras la denuncia pública, se decidió iniciar la investigación desde el Ministerio Público Fiscal. Pero hasta el momento se desconocen los resultados de este seguimiento (Página 12, de 2020: párr 2).

En la misma nota, Villanueva dio cuenta del crecimiento vertiginoso en la concurrencia de familias que sistemáticamente comenzaron a asistir al comedor desde el inicio de la pandemia “(...) cuando se inició la pandemia se elevó a 112 personas y empezamos a aceptar abuelos y familias completas porque hay gente que se enfermó de covid-19 y se quedó sin trabajo y no consigue" (Página 12, 2020: párr 8).

A comienzos de 2020, el Defensor del Pueblo delegado en Salta y activo colaborador de la mesa de Barrios Populares ${ }^{16}$ de la provincia, Félix González Bonorino, había hecho explícitas las condiciones de- 
gradadas ${ }^{17}$ en las que llegaba la asistencia de alimentos a algunos de los merenderos y comedores de los barrios más pobres de la capital salteña, en el marco de las medidas de aislamiento sanitario y ante la exigencia de protocolos de higiene en comunidades que carecen de agua, entre otros insumos necesarios para cumplimentar medidas requeridas por el propio gobierno.

\section{Las mujeres del comedor hablan poco y trabajan mucho18}

En uno de los comedores que se ubica en Floresta baja del sector norte, se disponen a preparar la merienda un grupo de mujeres, madres todas ellas, y lo hacen en perfecta sincronía silenciosa. Las personas que hablan demasiado, en el recinto donde se maquina la labor comunitaria, quedan sumidas a un solipsismo que interpela inmediatamente a tomar un puesto: acomodar y cortar la leña, preparar el pan, colar el mate cocido, recibir a la gente, lavar y secar utensilios. Solo en el compromiso honesto que exige esa vorágine "del hacer" inmediato es que se puede "sacar charla" a las mujeres que ocupan el concurrido espacio social.

El comedor de Floresta baja funciona ya hace 34 años en el lugar, habiendo iniciado como "olla popular" en época de Alfonsín y si bien actualmente cuenta con un espacio físico propio, en un principio la comida y la merienda se brindaban desde las casas particulares de algunas de las vecinas responsables del mismo. Concurren al comedor entre 150/160 personas (entre niñes y personas adultas), aunque, nos advirtió una de las madres: "con la entrega de la tarjeta alimentar el número de familias mermó mucho"19.

17 Vecinas de los barrios comunicaron a González Bonorino que el maíz y los porotos llegaban con gorgojos y los productos de higiene vencidos (Página 12, 2020).

18 En este apartado se hace uso de codificaciones de una entrevista en profundidad realizada a un vecino y una entrevista grupal realizada a 5 vecinas. Dichos relevamientos se llevaron a cabo en un comedor y un merendero de Villa Floresta. Consideramos importante dar cuenta de los puntos de vistas de las personas que trabajan e interaccionan en estos espacios sociales, ya que sus palabras son útiles para dimensionar las experiencias desde las que se tematiza analíticamente en este artículo.

19 Replicó en el momento la vecina que la tarjeta alimentar se está entregando actualmente solamente a las madres que percibían AUH (Asignación Universal por Hijo) y recordó lo mencionado por el Presidente de la Nación respecto a que se entregaría dicho beneficio a las madres que tenían pensión de siete hijos/as y madres con niños con discapacidad. Aclaró que, de sus conocidas, todavía ninguna recibió la 
Nosotras creemos que lo alimentario es importante porque acá tenemos madres adolescentes, madres solas que si bien cobran la asignación por ahí no les alcanza y deben recurrir al comedor. Hay familias que alquilan, tienen que pagar el alquiler y ya no les alcanza para alimentar a sus chicos (...) Cubrir la comida para los chicos es importante, no es solamente llenarle la panza, porque sabemos que quizás esos chicos si no se los suplementara, estarían buscando en la basura, o vendiendo lapiceras y si vienen ya pueden estar más en sus casas, o estudiar más o jugar más (...) (Gloria, referente de comedor Floresta Baja, 28 de julio de 2021).

El comedor recibe partida alimentaria de Desarrollo Social de la Nación ${ }^{20}$ y del Ministerio de Desarrollo Social de la Provincia de Sal$\mathrm{ta}^{21}$. Dichos recursos, mencionan las vecinas, no llegan a cubrir la demanda real que la población del barrio le exige al comedor. Las mujeres a cargo aseguran también que ambas partidas llegan siempre con un mes de retraso:

Ahora mismo estamos como casi dos meses atrasados, ósea, ahora en agosto nos estarían dando para cocinar en julio, pero nos van a dar como a fin de agosto (...) nosotros nunca cerramos, siempre tenemos alguien que nos colabora con algo, el almacén que nos fía. La fundación salta crece que nos da azúcar y leche para la merienda y luego particulares que de vez en cuando traen (...) (Gloria, referente de comedor Floresta Baja, 28 de julio de 2021).

Ante el crecimiento de la demanda por alimento las mujeres referentes no pueden hacer nada, no se puede sumar más gente porque los recursos se ven limitados, aun así mantienen firme su compromiso comunitario y deciden no cerrar las puertas del comedor: lo que siempre falta tratan de completarlo haciendo lotas o rifas, aquellas personas 
que tienen negocios y particulares aportan porque saben que eso efectivamente se distribuye en la comunidad.

Lateralidad: los merenderos y comedores en Floresta son un reducto insalvable de urgencias, mientras las mujeres maquinan cómo llegar con el alimento que falta, se escuchan gritos estruendosos: son "las chiquitas y los changuitos" correteando entre las leñas y las abuelas que llegan con sus bolsas a sentarse como "esfinges” esperanzadas, dueñas de lo que no sobra en el lugar. A esas personas no "les podés decir que no", me replica Gloria. Hay eso de trinchera, de fosa de recursos aparentes que se desembarazan de toda mezquindad y lástima, porque allí la mayoría está por lo mismo. Los comedores devienen trincheras, refugio de acopio en las comunidades pobres ante la inercia de la precariedad y la muerte de los tiempos que corren.

Nos apropiamos de la noción de "trinchera" 22 que lateraliza Gramsci (2014) citando a Bronstein ${ }^{23}$ y a Ilich $^{24}$, para articular alegóricamente dos campos de acción estrechamente ligados en su época y del que se han valido la Ciencias Políticas y la Filosofía Política, entre otras; para interpretar la realidad: nos referimos al campo militar y al político. Para Gramsci una "guerra de trincheras" (guerra de posición) es lo contrario de lo que en táctica militar se denomina "guerra frontal” (guerra de movimiento). La guerra de trincheras se desenvuelve como movimiento táctico de pertrechamiento de armas, municiones y abastecimiento de recursos en general, cuando estratégicamente no es conveniente o, no es posible la guerra frontal.

Enlazamos esta metáfora para pensar a los comedores/ merenderos como trincheras populares, porque entendemos que al cabo de más de un año de pandemia y frente a las múltiples restricciones sanitarias y económicas. Ante la falta de trabajo, los merenderos y comedores

22 Tomamos alegóricamente el aspecto metafórico e iterado de "trinchera" que, desde los medios y redes de comunicación social se usó en torno a la metáfora bélica, para rearticularlo semánticamente desde lugares de enunciación diferentes: los comedores y merenderos. No pretendemos hacer uso de la "traducción" marxista en sentido estricto trabajada por Gramsci sobre dicha noción, ya que nuestra perspectiva metodológica y epistémica se posiciona desde un tratamiento analítico distinto al elaborado por los estudios gramscianos. Dicha perspectiva fue expuesta en la introducción de este trabajo.

23 En referencia al líder político revolucionario Lev Davídovich Bronstein, más conocido como Lev Trotski.

24 Refiriéndose al líder comunista revolucionario Vladímir Ilich Uliánov, alias Lenin. 
fungieron como espacio social de guarida, de sobrevivencia y acopio de los recursos mínimos articulados estratégicamente frente a la intermitente y en muchos casos ineficiente asistencia Estatal.

Los merenderos se configuran como trincheras populares en tiempos de pandemia. En ellos se practican tácticas cotidianas de resistencia (De Certeau, 2000) y políticas comunitarias (Fernández, 2021): modos comunitarios inusitados y creativos de resistencia (como los que se mencionaron más arriba) tendientes a hacer frente a la carestía de recursos en los sectores populares y a la crisis económica global actual. Mediante un abanico múltiple, heterogéneo y mancomunado, las trincheras se configuran como un "hogar ampliado", distinto al espacio privado y doméstico de la vivienda familiar, pero estrechamente comunicado y complementario a este. La trinchera popular se afirma en el carácter comunitarista y se configura a su vez como refugio abierto al barrio: se monta como espacio activo de gestión y acopio de recursos que se distribuyen más o menos equitativamente "hacia dentro de la comunidad". No se trata de "refugiarse", sino de "hacer refugio" (Zaragoza Bernal, 2020), de construir sobre la base de la urgencia "casamatas" comunitarias, amalgamadas por la multiplicidad que la comunidad concurrente constituye, la cual desborda los muros de los habitáculos personales, que por otra parte, jamás pudieron contener al momento de las restricciones del aislamiento en los barrios populares.

Las trincheras populares fueron y son bálsamos de contención social y cuidado: nos contaron las personas que allí trabajan de los múltiples casos de denuncia por violencia doméstica y de género que acrecentaron con las medidas de aislamiento obligatorio y, junto a la falta de trabajo y hambre generalizado en nuestra provincia y país, se sumaron al "campo de problemas" de la pobreza persistente que hubo que auxiliar y acompañar desde la cercanía territorial.

Los merenderos y comedores devienen trincheras de resistencia, desde allí se articulan estrategias de visibilización y de denuncia ante infracciones que lesionan profundamente el tejido de derechos fundamentales, aquellos que se fueron ganando en las luchas desde los sectores populares: uno de ellos es el derecho a recibir asistencia estatal en tiempo y forma, cuando por sus medios y sus escasos recursos inmediatos las poblaciones pobres no pueden abastecerse. La tensión 
por el ejercicio del derecho a la asistencia desde las comunidades se configura en una lucha constante, desde dicho locus de enunciación los grupos que habitan los barrios populares de Salta se afirman en procura de la vida, ya que del alimento para asegurar la vida se trata en primera instancia, entre otras necesidades que acucian.

Al tiempo de la espera, se suma el de la incertidumbre, y no hay duda que las políticas implementadas por el Consejo Nacional de Argentina contra el Hambre son parte estratégica para contener la crisis, entre otras políticas destinadas a paliar la situación que se vive con extrema premura desde los barrios populares de Salta capital. Con todo, es preciso realizar un profundo llamado de atención, respecto a los modos en los que se gestiona y se efectiviza la asistencia hoy en nuestra provincia y en el país. El no hacerlo contribuiría a normalizar lógicas que desatienden el principio de derecho, esas mismas lógicas de la residualidad y la vejación que perviven y se reifican en torno a lo que implica asistir a "la ciudadanía” actualmente.

\section{Reflexiones finales}

Las trincheras populares, es decir los comedores y merenderos de Floresta, no cierran, se reconstituyen, se multiplican ${ }^{25}$. No se sabe a ciencia cierta en que momento surge la astucia de las personas que allí concurren, para administrar o producir recursos donde siempre "falta lo que falta”.

En torno a algunas de las preguntas suscitadas más arriba concluimos este apartado tomando argumento de la experiencia: creemos que es urgente amalgamar modos cercanos de trabajo activo y honesto entre áreas de gobierno en Salta (Desarrollo Social y Municipio, entre otras) para efectivizar canales de asistencia directa, más allá de los existentes, ya que los actuales se tornan ineficientes. Consideramos que si los gobiernos locales tomaran en serio los modos de organización de las comunidades de los barrios populares, partiendo desde esos locus de precariedad, entenderían de qué manera administrar los 
recursos sociales de la población toda, incluso respecto a la manera de optimizarlos en su distribución y circuitos.

Es claro que las comunidades tienen modos de apelar y ejercer el derecho a la asistencia. En tanto aquellas personas que cumplen funciones de intermediación estatal ralentizan u omiten su labor para el acceso a recursos y/o servicios de prestación social a las comunidades que los demandan (como en los casos aquí suscitados), las barriadas organizadas apelan a otras instancias de visibilización, de denuncia y de gestión para hacer valer sus derechos. Así resisten muchos grupos que sobreviven en los barrios periféricos de la capital salteña.

En las trincheras populares se produce un germen benigno que socava y agrieta profundamente la lógica de destrucción de "lo social". Aquello de lo que nos precavía Wendy Brown respecto del ataque medular de la racionalidad neoliberal. Si la embestida del neoliberalismo es a la sociedad y a sus instituciones y, si la democracia está más allá del Estado (Brown, 2020), pues debiéramos practicar democracia institucional, "iniciando" allí, donde tradicionalmente no se encontraban formas activas de ejercer derechos, por fuera de los circuitos clásicos de "lo institucional-estatal", pero sin prescindir de "lo estatal".

Quizás estas trincheras de "lo popular" actúen de manera aleccionadoramente política en los tiempos de crisis que vivimos. Desde estos lugares de la "negatividad" 26 (de la precariedad y la insuficiencia material) tal vez habite la posibilidad de comprender otras alternativas de encarar la discusión sobre las maneras de administrar y destinar bienes y servicios para garantizar vidas dignas de ser vividas. Desde esas territorialidades, puntos de paralajes inusitados e impensados para las burocracias modernas, tal vez habiten modos reconfigurados de pensar las estrategias tendientes a reposicionar el status de la asistencia como derecho.

\section{Referencias bibliográficas}

Álvarez Leguizamón, Sonia. (2015). Neocolonialismo, capitalismo, pobreza y resistencia subalterna. Rosario, Argentina, Protohistoria Ediciones. 
ANSES (2020). Ingreso Familiar de Emergencia. ANSES. Recuperado de: https:// www.anses.gob.ar/ingreso-familiar-de-emergencia

Brown, Wendy (2020). En las ruinas del neoliberalismo. El ascenso de las políticas antidemocráticas en occidente. Ciudad Autónoma de Buenos Aires, Argentina, Tinta Limón.

Campana Alabarce, Melisa (2014). Desarrollo Humano, producción social de la pobreza y gobierno de la pobreza. Revista Trabajo Social, 16(16), 79-89. Recuperado de: https://revistas.unal.edu.co/index.php/tsocial/article/view/47059

Campana Alabarce, Melisa (2018). La asistencia social como derecho: integración y precariedad. Escenarios. Revista de Trabajo Social y Ciencias Sociales, 27(27). Recuperado de: https://revistas.unlp.edu.ar/escenarios/article/view/8084

Campana Alabarce, Melisa (2020). "Hacia una ley nacional de Asistencia Social". En M. Campana, y M. E. Hermida (Eds.), La asistencia como derecho. Por una ley nacional de asistencia social (51-57). Ciudad Autónoma de Buenos Aires, Argentina, Espacio editorial.

Castel, Robert (1997). La metamorfosis de la cuestión social. Una crónica del salario. Buenos Aires, Argentina, Paidós.

Castro Gómez, Santiago (2010). Historia de la gubernamentalidad. Razón de Estado, liberalismo y neoliberalismo en Michel Foucault. Bogotá, Colombia, Siglo de hombres editores - Pontifica Universidad Javeriana - Instituto Pensar.

Clemente, Adriana (2014). "Sobre la pobreza como categoría de análisis e intervención”. En A. Clemente (Ed.), Territorios urbanos y pobreza persistente (23-50). Ciudad autónoma de Buenos Aires, Argentina, Espacio.

Comedores y merenderos afirman que la comida no alcanza (26 de abril de 2020) Página 12. Recuperado de: https://www.pagina12.com.ar/262208-comedores-y-merenderos-afirman-que-la-comida-no-alcanza

De Certeau, Michel (2000). La invención de lo cotidiano I. Artes del hacer. México, Universidad Iberoamericana. Biblioteca Xavier Clavigero.

De Sousa Santos, Boaventura (2009). Una epistemología del SUR. México, Siglo XXI, CLACSO.

El índice de pobreza bajó en Salta durante la segunda mitad de 2020 (01 de abril de 2021) Página 12. Recuperado de: https://www.pagina12.com.ar/333113-el-indicede-pobreza-bajo-en-salta-durante-la-segunda-mitad-

Fernández, Gonzalo Juan José (2021). Discursos de gobierno y tácticas de resistencia desde los barrios populares (Salta-Argentina-2020): derivas analíticas de la pandemia. Revista Intervención, 10(10), 62-76. Recuperado de: https://intervencion. uahurtado.cl/index.php/intervencion/article/view/91/121

Foucault, Michel (2011). Seguridad Territorio Población. Curso del Collegue de France: 1977-1978. Buenos Aires, Argentina, Fondo de Cultura Económica.

Foucault, Michel (2014). Defender la sociedad. Buenos Aires, Argentina, Fondo de Cultura Económica.

Giavedoni, José Gabriel (2012). Gobernando la pobreza. La energía eléctrica como dispositivo de gestión de los sectores populares. Rosario, Argentina, Homo Sapiens.

Gramsci, Antonio (1981). Cuadernos de la cárcel Tomo 2. México, ERA.

Gramsci, Antonio (2014). Antología Vol. 2. Buenos Aires, Argentina, Siglo XXI. 
Hirtz, Nicolás (12 de octubre de 2020) Comedores comunitarios lugares de resistencia contra la crisis. Página 12. Recuperado de: https://www.pagina12.com. ar/298566-comedores-comunitarios-lugares-de-resistencia-contra-la-cris

Instituto Nacional de Estadísticas y Censos (INDEC) (2021). Pobreza. Instituto Nacional de Estadísticas y Censos República Argentina. Recuperado de: https://www. indec.gob.ar/indec/web/Nivel3-Tema-4-46

Les negaron la mercadería y por tres días no hubo comedor $(27$ de diciembre de 2020) Página 12. Recuperado de: https://www.pagina12.com.ar/313842-les-negaron-la-mercaderia-y-por-tres-dias-no-hubo-comedor

Merklen, Denis (2010). Pobres ciudadanos. Las clases populares en la era democrática (Argentina, 1983- 2003). Buenos Aires, Argentina, Gorla.

Ministerio de Desarrollo Social (2021). Argentina contra el hambre. Argentina.gob. ar. Recuperado de: https://www.argentina.gob.ar/argentina-contra-el-hambre

Ministerio de Desarrollo Social (2021). Registro Nacional de Merenderos y Comedores Comunitarios (RENACOM). Argentina.gob.ar. Recuperado de: https://www. argentina.gob.ar/desarrollosocial/renacom

Ministerio de Trabajo, Empleo y Seguridad Social (2021). Programa de Recuperación Productiva 2 (REPRO 2). Argentina.gob.ar, Recuperado de: https://www. argentina.gob.ar/trabajo/repro2

Murillo, Susana (2008). Colonizar el dolor. Buenos Aires, Argentina, CLACSO.

Noviasky, Silvia (23 de enero de 2021) Aseguran que los comedores se cuadruplican en Salta. El tribuno. Recuperado de: https://www.eltribuno.com/salta/nota/2021-129-0-0-0-aseguran-que-los-comedores-se-cuadruplicaron-en-salta

Paulizzi, Cora María (2020). Entre Gobernados y Gobernantes Los programas de gobierno dirigidos a las poblaciones pobres-desocupadas y las prácticas de resistencia y autogobierno en Salta, Argentina. El caso de la Unión de Trabajadores en Gral. Moscóni (tesis doctoral). Catamarca, Argentina, Universidad Nacional de Catamarca.

Preciado, Beatriz Paul (2020). “Aprendiendo el Virus”. En P. Amadeo (Ed.), Sopa de Wuhan. Buenos Aires, Argentina, ASPO.

Rose, Nikolas (2007). ¿La muerte de lo social? Re-configuración del territorio de gobierno. Revista Argentina de Sociología, 5(8), 111-150. Recuperado de: https:// www.redalyc.org/articulo.oa?id=26950807

Zaragoza Bernal, Juan Manuel (2021). Refugio o trinchera: reflexiones sobe el hogar durante la pandemia. Revista de Filosofía eikasia, 98(98), 139-162. Recuperado de: https://dialnet.unirioja.es/servlet/articulo?codigo $=7873187$

Recibido: 08/08/21

Aceptado: 12/10/21 